Industrial Health, 1985, 23, 145-153

\title{
Allergic Contact Dermatitis from Organophosphorus Insecticides
}

\author{
Toshio MATSUSHITA*, Kohji AOYAMA*, Kazumitsu YOSHIMI* \\ Yasuyuki FUJITA** and Atsushi UEDA* \\ * Department of Hygiene, Faculty of Medicine, \\ Kagoshima University, Usuki-cho, Kagoshima 890, Japan \\ ** Department of Public Health, Jichi Medical School, \\ Tochigi Prefecture, Japan
}

(Received September 25, 1984 and in revised form February 26, 1985)

\begin{abstract}
To clarify the conditions and the mechanism of contact dermatitis from organophosphorus insecticides, case analysis of 202 patients with contact dermatitis from organophosphorus insecticides, who were collected from all over the country in cooperation with the members of the Japanese Association of Rural Medicine, and some related experiments were undertaken. The results were as follows:

1. From the case analysis, the solitary compounds of organophosphorus insecticides chiefly attributed to the dermatitis were DDVP, salithion, sumithion, phosvel, cyanox, kilval, diazinon and malathion in order.

2. The regions of the dermatitis were finger $(62.4 \%)$, face $(39.6 \%)$, forearm $(31.7 \%)$, neck and nape $(29.7 \%)$ and so forth.

3. About one quarters $(25.2 \%)$ of the cases with the dermatitis had complication with symptoms of acute poisoning from organophosphorus compounds. The rates of patients ragarding the prognosis of the dermatitis were relatively high in healed cases $(44.1 \%)$ and in treatment cases $(27.2 \%)$, but about one fourth of the patients $(23.8 \%$ ) were left in incomplete healing.

4. From the animal experiment, relatively strong degree of primary irritating reactions on the skin of guinea pigs were observed especially in such insecticides as DDVP.

5. Potency of allergenicity predicted by the guinea pig maximization test was relatively high (grade III to V) for such organophosphorus compounds as diazinon, fenitrothion and supracide. Apparent cross reactions were observed between supracide and DDVP or dibrom, but they were lower in such cases between organophosphorus insecticides and other pesticide series as benzimidazole and carbamates.
\end{abstract}

Key words: Allergic contact dermatitis-Organophosphate-Insecticide-DDVPFenitrothion-Diazinon-Supracide 


\section{INTRODUCTION}

Despite the extensive use of pesticides in agriculture and horticulture, dermatitis from the pesticides has been regarded to be rare. ${ }^{1)}$

As for the toxicity of organophosphorus insecticides, systemic symptoms caused by cholinesterase-inhibiting effect have been given attention. They are rarely implicated in dermatitis, chiefly because they are usually handled with considerable care, and only sporadic reports were presented from such pesticides as parathion, ${ }^{3-5)}$ naled, ${ }^{6)}$ dichlorvos, ${ }^{7-9)}$ chlorfenvinphos ${ }^{10)}$ and Plondrel (Ditalimfos ). ${ }^{11)}$ According to our study, ${ }^{2)}$ a total of 815 patients suffering from pesticide poisoning, including 316 cases $(38.8 \%)$ ) with skin lesions, were reported during 1968-1970 in Japan, and $55(17.4 \%)$ out of 316 cases of this skin lesions were diagnosed to be contact dermatitis caused by organophosphorus insecticides. Therefore, the incidence of dermatitis due to organophosphorus pesticides seems to be not uncommon in the actual circumstances.

The purpose of this study is to clarify the actual condition and an occurrence mechanism of the dermatitis in more detail from case analysis and some related experiments.

\section{Materials and Methods}

Case analysis: A total of 553 patients suffering from skin lesions due to pesticides, including 202 cases (male 130, female 72 ) (36.5\%) with dermatitis from organophosphorus insecticides, were reported from all over the country by the members of the Japanese Association of Rural Medicine from 1972 to 1979. Then, the 202 cases were analysed in the present study. The greater part of the cases were farmers spraying various kinds of organophosphorus compounds. The causative pesticides of the dermatitis, regions of eruption, complication with the dermatitis and prognosis of the dermatitis were investigated from the cases.

Experimental study: To clarify the character of some organophosphorus insecticides in regard to the skin, this experiment was undertaken. The compounds tested in the present study were in technical grade and as follows;

DDVP (2,2-dichlorovinyl dimethyl phosphate), diazinon (diethyl 2-isopropyl4-methyl-6-pyrimidinyl phosphorothionate), dibrom (naled; 1,2-dibromo-2,2dichloroethyl dimethyl phosphate), fenitrothion (sumithion; 0,0-dimethyl 0(3-methyl-4-nitrophenyl)thiophosphate), kilval (vamidothion; dimethyl S[2-(1-methylcarbamoylethylthio)ethyl] phosphorothionate), kitazin P (0,0diisopropyl-s-benzyl thiophosphate), malathion (S-1,2-bis (ethoxycarbonyl) ethyl-0,0-dimethyl thiophosphate), phosvel (0-methyl-0-(4-bromo-2,5-dichlorophenyl)phenyl phosphorothioate), and supracide (0,0-dimethyl-s-[5-methoxy-1,3,4-thiadiazole-2-(3H) onyl-(3) methyl]dithiophosphate). 
The test compounds were diluted with distilled water, and their solutions or emulsions were prepared for each experiment.

Threshold limit values for primary irritating effect of test chemicals on skin of guinea pigs.

Threshold limit values for primary irritating effect of the test compounds on the skin of guinea pigs were determined to estimate their irritancy and to decide challenging topical concentrations used in the latter experiment. Albino female guinea pigs of Hartley strain weighing about $500 \mathrm{~g}$ were used for this experiment. Five animals were used in each group. They were cripped and shaved in advance. The test preparations were closely patched using Testpflaster ${ }^{\otimes}$ for 24 hrs around the flank and the reactions were read at $2 \mathrm{hrs}$ after removal of the patches. The concentrations adopted in this experiment were 20,10,5,2,1 and 0.5 per cent. The lowest concentration of a test compound revealing skin erythema was decided to be threshold limit value for irritating reaction.

Potency of allergenicity predicted by the guinea pig maximization test.

The guinea pig maximization test (Magnusson and Kligman $)^{12,13)}$ was undertaken to study the allergenicity of the organophosphorus insecticides. Hartley female guinea pigs weighing from 300 to $500 \mathrm{~g}$ were used for the experiment. Ten animals were served in each group. Induction and challenge were undertaken according to the original method. The topical concentrations applied for the challenge were less than the threshold limit values determined in the former experiment. The concentrations of the compounds used for the induction and challenge are indicated in Tables 6 and 7 . Using the procedure developed by Kligman, ${ }^{14)}$ the results of maximization testing were graded into five classes, ranging from weak (grade I) to extreme (grade V) according to the percentage of animals sensitized (see: Table 1).

Cross sensitizations among organophosphorus insecticides and some other pesticides.

In order to estimate the cross sensitizations among organophosphorus insecticides and/or some other pesticides, this experiment was carried out. The animals used for the study and the induction procedure were alike the former experiment. The animals were challenged by a few another preparations applied for

Table 1. The sensitization ranking proposed by Kligman (1966)

\begin{tabular}{ccl}
\hline Sensitization rate $(\%)$ & Grade & \multicolumn{1}{c}{ Rank } \\
\hline $0-8$ & I & Weak \\
$9-28$ & II & Mild \\
$29-64$ & III & Moderate \\
$65-80$ & IV & Strong \\
$81-100$ & V & Extreme \\
\hline
\end{tabular}


the induction, and the cross sensitizations were evaluated by reading of challenged reactions.

\section{RESUlTS}

Case analysis: 130 cases $(64.4 \%)$ out of a total 202 patients with dermatitis from organophosphorus insecticides were the males. The 202 patients were classified by the number of causative pesticides as 'solitary compound' and 'numerous compounds'. The group of numerous compounds $(75.2 \%)$ was an absolute majority compared with that of solitary compound $(24.8 \%)$ (Table 2). The insecticides of solitary compound chiefly attributed to the dermatitis were DDVP, salithion, sumithion, phosvel, cyanox, kilval, diazinon and malathion in order (Table 3). The skin regions of dermatitis from organophosphorus insecticides were such as finger $(62.4 \%)$, face $(39.6 \%)$, forearm $(31.7 \%)$, neck and nape

Table 2. Dermatitis from organophosphorus insecticides in Japan (1972-1979)

\begin{tabular}{lccr}
\hline \multirow{2}{*}{ Case } & \multicolumn{2}{c}{ Causative pesticide } & \multirow{2}{*}{ Total } \\
\cline { 2 - 4 } & Solitary compound & Numerous compound & \\
\hline Male & $23(46.0)$ & $107(70.4)$ & $130(64.4)$ \\
Female & $27(54.0)$ & $45(29.6)$ & $72(35.6)$ \\
\hline Total number & $50(100.0)$ & $152(100.0)$ & $202(100.0)$ \\
& {$[24.8]$} & {$[75.2]$} & {$[100.0]$} \\
\hline
\end{tabular}

* Case were collected from all over the country in cooperation with the members of the Japanese Association of Rural Medicine.

Table 3. Causative organophosphorus insecticides of dermatitis

\begin{tabular}{lcc}
\hline Pesticide & Solitary & Numerous \\
\hline DDVP & 11 & 55 \\
Salithion & 4 & 37 \\
Phosvel & 4 & 23 \\
Sumithion & 3 & 24 \\
Malathion & 3 & 15 \\
Diazinon & 2 & 16 \\
Kitazin P & 2 & 3 \\
Cyanox & 0 & 22 \\
Kilval & 0 & 20 \\
Disyston & 0 & 4 \\
Supracide & 0 & 3 \\
Others & 21 & 70 \\
\hline Total & 50 (100) & 152 (100) \\
\hline * Solitary" and “numerous" mean that the dermatitis was \\
estimated to be occurred by a solitary compound and numer- \\
ous compounds in use, respectively.
\end{tabular}


$(29.7 \%)$, chest and back (18.8\%) and shank (16.8\%) in order (Table 4). And, the type of skin lesions was classified as contact dermatitis. 51 cases ( $25.2 \%)$ out of 202 patients with dermatitis had a complication with symptoms of acute poisoning. The rates of patients regarding the prognosis of the dermatitis were relatively high in healed cases $(44.1 \%)$ and in treatment cases $(27.2 \%)$, but about one fourth of the cases $(23.8 \%)$ were left in incomplete healing.

Experimental study: Threshold limit values for primary irritating effect of organophosphorus compounds on skin of guinea pigs.

The threshold limit values for primary irritancy of organophosphorus compounds on the skin of guinea pigs were shown in Table 5. The value of DDVP was $2 \%$ or more, and those of diazinon, dibrom, fenitrothion, kilval and mala-

Table 4. Regions of dermatitis from organophosphorus insecticides

\begin{tabular}{lc}
\hline Region & Case number \\
\hline Face & $80(39.6)$ \\
Neck and nape & $60(29.7)$ \\
Chest and back & $38(18.8)$ \\
Abdomen & $15(7.4)$ \\
Waist and hip & $12(5.9)$ \\
Finger & $126(62.4)$ \\
Forearm & $64(31.7)$ \\
Upper arm & $29(14.4)$ \\
Toe & $13(6.4)$ \\
Shank & $34(16.8)$ \\
Thigh & $27(13.4)$ \\
Others & $7(3.5)$ \\
\hline Total & $202(100.0)$ \\
\hline
\end{tabular}

* There are some overlapping in numbers.

Table 5. Threshold limit values for primary irritating effect of organophosphorus pesticides on skin of guinea pigs

\begin{tabular}{lc}
\hline Pesticide & Threshold limit values (\%) \\
\hline DDVP & 2 or more \\
Diazinon & 10 or more \\
Dibrom & 10 or more \\
Fenitrothion & 10 or more \\
Kilval & 10 or more \\
Kitazin $P$ & more than 20 \\
Malathion & 10 or more \\
Phosvel & more than 20 \\
Supracide & more than 20
\end{tabular}

* The test chemicals were diluted with distilled water. The values were estimated using $24 \mathrm{~h}$ closed patch test by the compounds. 
thion were $10 \%$ or more, and those of kitazin $\mathrm{P}$, phosvel and supracide were more than $20 \%$, respectively. From the results of this experiment, the challenging topical concentrations of those compounds for allergenicity test were decided below the concentrations of these values as found in Tables 6 and 7 .

Potency of allergenicity predicted by the guinea pig maximization test.

As indicated in Table 6, the allergenicity ratings for organophosphorus compounds tested at 24 and $48 \mathrm{hrs}$ readings were ranging from grade I to V. Relatively high incidence rates of positive reactions, from grade III to V., were found in such compounds as diazinon, fenitrothion and supracide and low incidence rate was found for phosvel. The incidence rates were comparatively lower in group of low challenging concentrations than those of high concentrations, especially in dibrom, kitazin $\mathbf{P}$ and malathion.

Cross sensitizations among organophosphorus insecticides and/or some other pesticides.

As shown in Table 7, the allergenicity ratings for the cross reactions of some organophosphorus compounds with other pesticides were estimated to be ranging from grade I to IV in potency of causing contact sensitizations. Apparent cross

Table 6. Allergenicity of organophosphorus pesticides predicted by guinea pig maximization test

\begin{tabular}{|c|c|c|c|}
\hline \multirow{2}{*}{ Pesticide } & \multirow{2}{*}{ Challenge conc. (\%) } & \multicolumn{2}{|c|}{ Allergenicity rating } \\
\hline & & $24 \mathrm{~h}$ & $48 \mathrm{~h}$ \\
\hline DDVP & $\begin{array}{l}0.5 \\
0.05\end{array}$ & $\begin{array}{r}\text { III }\left(\begin{array}{r}30 \\
\text { I }\end{array}\right) \\
0\end{array}$ & III $\left(\begin{array}{r}40 \\
\text { I }\end{array}\right)$ \\
\hline Diaginon & $\begin{array}{l}0.5 \\
0.05\end{array}$ & $\begin{array}{r}\mathrm{V}(100) \\
\text { III }(30)\end{array}$ & $\begin{array}{r}\text { V }(100) \\
\text { III }(30)\end{array}$ \\
\hline Dibrom & $\begin{array}{l}2 \\
0.2\end{array}$ & $\begin{array}{l}\text { IV }(80) \\
\text { I }\left(\begin{array}{l}8 \\
0\end{array}\right)\end{array}$ & $\begin{array}{c}\text { V }(90) \\
\text { I }\left(\begin{array}{r}9 \\
0\end{array}\right)\end{array}$ \\
\hline Fenitrothion & $\begin{array}{l}5 \\
0.5\end{array}$ & $\begin{array}{l}\text { IV }(70) \\
\text { III }(30)\end{array}$ & $\begin{array}{l}\text { IV }(70) \\
\text { III }(40)\end{array}$ \\
\hline Kilval & $\begin{array}{l}5 \\
0.5\end{array}$ & $\begin{array}{c}\text { III } \\
\text { II }\left(\begin{array}{l}40 \\
(10)\end{array}\right.\end{array}$ & II $\left(\begin{array}{r}20 \\
0\end{array}\right)$ \\
\hline Kitazin $\mathbf{P}$ & $\begin{array}{l}5 \\
0.5\end{array}$ & 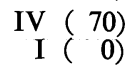 & $\begin{array}{l}\text { V }\left(\begin{array}{r}90 \\
\text { II }\end{array}\right. \\
0)\end{array}$ \\
\hline Malathion & $\begin{array}{l}2 \\
0.2\end{array}$ & $\begin{array}{l}\text { IV }(70) \\
\text { II }(10)\end{array}$ & III $\quad\left(\begin{array}{r}60) \\
\text { I }\end{array}\right.$ \\
\hline Phosvel & $\begin{array}{l}2 \\
0.2\end{array}$ & 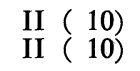 & $\begin{array}{l}\text { II }\left(\begin{array}{l}10 \\
\text { II }\end{array}(10)\right.\end{array}$ \\
\hline Supracide & $\begin{array}{l}5 \\
0.5\end{array}$ & $\begin{array}{r}\text { V }(90) \\
\text { III }(90)\end{array}$ & $\begin{array}{l}\text { IV }(80) \\
\text { III }(40)\end{array}$ \\
\hline
\end{tabular}

\footnotetext{
* Intradermal and topical concentrations used for induction with each pesticides were $5 \%$ and $25 \%$, respectively.

Allergenicity ratings were estimated at 24 and $48 \mathrm{~h}$ after removal of the $24 \mathrm{~h}$ closed patch, and shown by grade, ranging weak (grade I) to extreme (grade V), using a procedure developed by Kligman. (1966).

The numerals inside parentheses indicate the percentage of sensitized animals.
} 
Table 7. Cross sensitizations between some organophosphorus insecticides and other pesticides

\begin{tabular}{|c|c|c|c|}
\hline \multirow{2}{*}{$\frac{\text { Induction }}{\text { Pesticide }}$} & \multicolumn{3}{|c|}{ Challenge } \\
\hline & Pesticide & Topical conc. (\%) & Allergenicity rating \\
\hline Diazinon & Benlate & $\begin{array}{l}2 \\
0.2\end{array}$ & $\begin{array}{r}\text { III }(30) \\
\text { I }(0)\end{array}$ \\
\hline DDVP & Zineb & $\begin{array}{l}2 \\
0.2\end{array}$ & 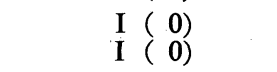 \\
\hline Fenitrothion & Benlate & $\begin{array}{l}2 \\
0.2\end{array}$ & $\begin{array}{r}\text { II } \\
\text { I }(20)\end{array}$ \\
\hline Fenitrothion & Lannate & $\begin{array}{l}5 \\
0.5\end{array}$ & 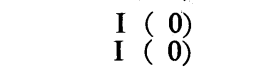 \\
\hline Fenitrothion & Zineb & $\begin{array}{l}2 \\
0.2\end{array}$ & $\begin{array}{l}\text { I }\left(\begin{array}{l}0 \\
\text { I }\end{array}\right) \\
0\end{array}$ \\
\hline Kitazin $\mathbf{P}$ & Benlate & $\begin{array}{l}2 \\
0.2\end{array}$ & $\begin{array}{r}\text { II }(20) \\
\text { I }(0)\end{array}$ \\
\hline Malathion & Lannate & $\begin{array}{l}5 \\
0.5\end{array}$ & $\begin{array}{l}\text { I }\left(\begin{array}{l}0 \\
\text { I }\end{array}\right) \\
0\end{array}$ \\
\hline Malathion & Zineb & $\begin{array}{l}2 \\
0.2\end{array}$ & $\begin{array}{l}\text { I }\left(\begin{array}{l}0 \\
\text { I }\end{array}\right) \\
0\end{array}$ \\
\hline Supracide & Benlate & $\begin{array}{l}2 \\
0.2\end{array}$ & $\begin{array}{r}\text { II }(10) \\
\text { I }(0)\end{array}$ \\
\hline Supracide & DDVP & $\begin{array}{l}0.5 \\
0.05\end{array}$ & $\begin{array}{l}\text { IV }(80) \\
\text { II }(25)\end{array}$ \\
\hline Supracide & Dibrom & $\begin{array}{l}2 \\
0.2\end{array}$ & $\begin{array}{c}\text { IV }(65) \\
\text { II }(20)\end{array}$ \\
\hline
\end{tabular}

* Intradermal and topical concentrations used for induction with each chemicals were $5 \%$ and $25 \%$, respectively.

The allergenicity ratings are shown by mean values of reading at 24 and $48 \mathrm{~h}$ after removal of the $24 \mathrm{~h}$ closed patch testing.

reactions were observed between supracide and DDVP or dibrom. However, they were lower in such a case between organophosphorus insecticides and other pesticide series such as benzimidazole (benomyl) and carbamates (lannate, zineb).

\section{DISCUSSION}

A large number of organophosphorus insecticides have been used widely in many countries. Organophosphorus compounds have been generally considered to have little or no primary irritation, so skin contact of the compounds may pass unnoticed and cause systemic poisoning. ${ }^{15,16)}$ Accordingly, there are relatively few reports on the occurrence of skin lesions responsible to those pesticides. That is, as mentioned previously, such as parathion, naled, dichlorvos, chlorfenvinphos and Plondrel alone are reported to cause dermatitis. But, the incidence rate of contact dermatitis from organophosphorus compounds in our previous study ${ }^{2)}$ was $17.4 \%$, and this was $36.5 \%$ in the present survey. To clarify the designed detailed features of contact dermatitis, the present study was conducted. 
From the case analysis, causative organophosphorus compounds chiefly attributed to the occurrence of contact dermatitis were found to be DDVP, salithion, sumithion (fenitrothion), phosvel, cyanox, kilval, diazinon and malahion in order. But, the character of this contact dermatitis was not yet clarified. Then, in order to estimate their irritancy and allergenicity on the skin, some animal experiments were undertaken. Primary irritating reaction was relatively strong for such insecticide as DDVP. Relatively high potency (grade III to V) of allergenicity was predicted by the guinea pig maximization test for such organophosphorus compounds as diazinon, fenitrothion and supracide. On the other hand, it was weak in the case of phosvel. Allergenicity ratings for dibrom, kitazin $\mathbf{P}$ and malathion were considerably less in low challenging concentrations than in high concentrations.

Concerning to the dermatitis from malathion, it was shown that the allergen in malathion was not the chemical itself, but diethyl fumarate present as a contaminant. ${ }^{17)}$ Therefore, the present results may be modified by such contaminants, because organophosphorus compounds used in the present study were in technical grade. Occupational dermatitis from naled (dibrom) was also reported in four women cutting chrysanthemums. ${ }^{6}$ ) But, there are scarcely any reports on the dermatitis from the other insecticides taking up in the present study.

The cross sensitizations among chemicals are an important problem for the prevention of contact dermatitis. The cross reactions among some chemicals, such as halogenated benzene compounds ${ }^{18)}$ and other compounds, ${ }^{19-22)}$ have been shown. Then, it was very interesting that apparent cross reactions were observed among organophosphorus compounds, namely, between supracide and DDVP or dibrom. But, it was obscure in the case of organophosphorus compounds and other pesticides such as benzimidazole (benomyl) and carbamates (lannate, zineb).

It is generally known that many factors contribute to the outbreak of dermatitis from agricultural chemicals. ${ }^{23)}$ That is, sensitization due to pesticides in man, is not directly related to the allergenicity of the substances themselves but is influenced by such factors as the concentration in use, the method it will be used, the presence of impurities in the compounds and some environmental factors. Accordingly, further investigations are indispensable to confirm the occurrence of dermatitis from those organophosphorus compounds in great detail.

\section{ACKNOWLEDGEMENTS}

The authors would like to thank the members of the Japanese Association of Rural Medicine for their kind collaboration in this investigation and also Miss Etsuko Kamiiriki for her skilled technical assistance.

This study was supported in part by a Grant-in-Aid for Scientific Research (No. 59570231) of the Ministry of Education, Science and Culture. 


\section{REFERENCES}

1) Fregert, S. and Hjorth, N. (1968). The principal irritants and sensitizers. In: Textbook of Dermatology, p. 1888 (Edited by Rook, A. et al.), Blackwell, London.

2) Matsushita, T., Nomura, S. and Wakatsuki, T. (1980). Epidemiology of contact dermatitis from pesticides in Japan, Contact Dermatitis, 6, 255.

3) Palmintieri, G. (1966). On the experimental sensitization with diethyl paranitrophenyl thiophosphate (parathion), Ital. Gen. Rev. Dermatol., 7, 48.

4) Bhargava, R. K., Singh, V. and Soni, V. (1977). Erythema multiforms resulting from insecticide spray, Arch. Dermatol., 113, 686.

5) Pevny, I. (1980). Pestizid-Allergie, Dermatosen, 28, 186.

6) Edmundson, W. F. and Davies, J. E. (1967). Occupational dermatitis from naled, A clinical report, Arch. Environ. Health, 15, 89.

7) Müller, G. H. (1970). Flea collar dermatitis in animals, J. Am. Vet. Med. Assoc., 157, 1616.

8) Fregert, S. (1973). Allergic contact dermatitis from two pesticides, Contact Dermatitis Newsl., 7, 367.

9) Mathias, C. G. T. (1983). Persistent contact dermatitis from the insecticide dichlorvos, Contact Dermatitis, 9, 217.

10) Hunter, C. G. (1969). Dermal toxicity of chlorfenvinphos (CFVP), Ind. Med. Surg., 38, 49.

11) Van Ketel, W. G. (1975). Allergic dermatitis from a new pesticide, Contact Dermatitis, 1, 297.

12) Magnusson, B. and Kligman, A. M. (1969). The identification of contact allergens by animal assay. The guinea pig maximization test, J. Invest. Dermatol., 52, 268.

13) Magnusson, B. and Kligman, A. M. (1970). Allergic Contact Dermatitis in the Guinea Pigs, Thomas, Springfield.

14) Kligman, A. M. (1966). The identification of contact allergens by human assay. III. The maximization test. A procedure for screening and rating contact sensitizers, J. Invest. Dermatol., 47, 393.

15) Namba, T., Nolte, C. T., Jackrel, J., et al. (1971). Poisoning to organophosphorus insecticides, Am. J. Med. 50, 475.

16) Rycroft, R. J. G. (1977). Contact dermatitis from organophosphorus pesticides, Br. J. Dermatol., 97, 693.

17) Milby, T. H. and Epstein, W. L. (1964). Allergic contact sensitivity to malathion, Arch. Environ. Health, 9, 434.

18) Björnberg, A. and Mobacken, H. (1973). Sensitization to benzene compounds, Berufsdermatosen, 21, 245.

19) Baer, R. L., Leider, M. and Mayer, R. L. (1948). Possible eczematous cross-hypersensitivity between p-phenylenediamine and azodyes certified for use in foods, dyes and cosmetics, Proc. Soc. Exp. Biol. Med., 67, 489.

20) Pirila, V., Forstrom, L. and Rouhunkoski, S. (1967). Twelve years of sensitiziation to neomycin in Finland: Report of 1,760 cases of sensitivity to neomycin and/or bacitracin, Acta Dermatol. Venereol., 47, 419.

21) Samsoen, M., Metz, R., Melchior, E. et Foussereau, J. (1979). Allergie croisée entre les antibiotiques aminosides, Ann. Dermatol. Venereol., 106, 683.

22) Kozuka, T., Tashiro, M., Sano, S. et al. (1980). Pigmented contact dermatitis from azo dyes. I. Cross-sensitivity in humans, Contact Dermatitis, 6, 330.

23 ) West, I. (1964). Occupational disease of farm workers, Arch. Environ. Health, 9, 92. 